\title{
G

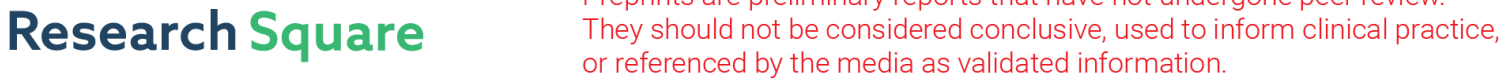 \\ The impact of intrauterine growth restriction (IUGR) on neonatal primary hemostasis
}

\section{Maria Kollia ( $\nabla$ kolliamaria10@gmail.com )}

Neonatal Department, Medical School, National and Kapodistrian University of Athens, Greece https://orcid.org/0000-0001-8957-688X

\section{Nicoletta lacovidou}

Neonatal Department, Medical School, National and Kapodistrian University of Athens, Greece

\section{Zoe lliodromiti}

Neonatal Department, Medical School, National and Kapodistrian University of Athens, Greece

\section{Abraham Pouliakis}

2nd Department of Pathology, National and Kapodistrian University of Athens, "Attikon" University Hospital, Athens, Greece

\section{Rozeta Sokou}

Neonatal Department, Medical School, National and Kapodistrian University of Athens, Greece

\section{Vasiliki Mougiou}

Neonatal Department, Medical School, National and Kapodistrian University of Athens, Greece

\section{Maria Boutsikou}

Neonatal Department, Medical School, National and Kapodistrian University of Athens, Greece

\section{Marianna Politou}

Haematology Laboratory-Blood Bank, Aretaieio Hospital, National and Kapodistrian University of

Athens, Greece

\section{Theodora Boutsikou}

Neonatal Department, Medical School, National and Kapodistrian University of Athens, Greece

\section{Serena Valsami}

Haematology Laboratory-Blood Bank, Aretaieio Hospital, National and Kapodistrian University of Athens, Greece https://orcid.org/0000-0002-1034-6510

\section{Research Article}

Keywords: IUGR, PFA-100, closure time, platelets, prematurity

Posted Date: October 25th, 2021

DOI: https://doi.org/10.21203/rs.3.rs-983873/v1 
License: (c) (i) This work is licensed under a Creative Commons Attribution 4.0 International License. Read Full License 


\section{Abstract}

Platelet function in IUGR neonates remain a field of debate, especially in preterm subgroup. Platelet Function Analyzer (PFA-100) offers a quantitative in vitro assessment of primary, platelet-related hemostasis. Our aim was to examine platelet function using PFA-100 in term and preterm IUGR neonates and associate our results with several perinatal parameters. PFA-100 was applied on 74 IUGR neonates, 48 full-term ( $>37$ weeks' gestation) and 26 preterm neonates (< 37 weeks' gestation). Control group consisted of 118 healthy neonates. Two CTs (with COL/EPI and COL/ADP cartridges) were determined on cord blood samples for each subject. COL/EPI CTs were prolonged in IUGR (median 132s) compared to control neonates (median 112,5s), $p=0.0371$. Median COL/EPI CT for term and preterm IUGR neonates was $126 \mathrm{~s}$ and $137 \mathrm{~s}$ respectively $(\mathrm{p}=0.0013)$, and COL/ADP CT was 70 s for term and $75 \mathrm{~s}$ for preterm IUGR neonates $(p=0.0827)$. COL/ADP CTs were shorter in IUGR neonates born via vaginal delivery $(p=0.0065)$, shorter after intrapartum antibiotic prophylaxis with ampicillin $(p=0.0045)$ and prolonged in neonates whose mothers received epidural anesthesia $(p=0.032)$. The cause of IUGR has no impact on CTs $(p>0.05$ in all cases). COL/EPland COL/ADP CTs had positive correlation ( $r=0.37, p<0.0012)$ whereas no correlation was proved between both CTs and hematological parameters in IUGR neonates.

Conclusions. IUGR neonates showed impaired platelet function, with preterm IUGR neonates confronting the greater risk for bleeding tendency. Prolonged COL/EPI CTs seemed to be independent of hematological parameters, especially thrombocytopenia of IUGR neonates.

\section{What Is Known And New: \\ - What is Known :}

Platelet function studies among IUGR neonates concern mainly neonates born to mothers with preeclampsia.

- Several studies report decreased platelet adhesion and expression of glycoproteins on activated platelets' surfaces.

- Studies using flow cytometry report higher in vitro platelet responsiveness.

\section{What is New:}

- Impaired platelet function observed via PFA-100 indicates that IUGR neonates could be at greater risk for bleeding tendency, especially preterm subpopulation.

\section{Introduction}

Intrauterine growth restriction (IUGR) refers to the failure of fetus to reach its intrinsic growth potential, due to pathologic causes of maternal, fetal, placental, or genetic origin [1-3]. IUGR affects $5-10 \%$ of all pregnancies peryear [4] and is one of the leading causes of perinatal and neonatal morbidity and 
mortality associated with long-term chronic diseases $[3,5,6]$. A main characteristic of IUGR neonates is thrombocytopenia with an incidence $31.5 \%$, three times higher compared to appropriate for gestational age (AGA) neonates [7-12]. Thrombocytopenia could be attributed to platelets' destruction caused by placental vascular pathology [13], shunt of stem cells to erythropoiesis due to intrauterine hypoxia [14], or immaturity of liver and spleen due to redistribution of blood flow and the brain-sparing effect. Early-onset thrombocytopenia is independently associated with lower gestational age (GA) at birth in IUGR neonates [8].

The investigation of neonatal platelet function in IUGR neonates remains an issue of ongoing research with conflicting results so far. Platelet function studies concern mainly neonates born to mothers with pregnancy induced hypertension (PIH), showing decreased platelet adhesion [15] and expression of glycoproteins on activated platelets' surfaces [16]. On the contrary, flow cytometry studies reported higher in vitro responsiveness of neonatal platelets to various agonists [17], while studies using thromboelastometry (TEM) did not report any difference in maximal clot firmness (MCF), a measure of platelet number and function [18]. Regarding preterm IUGR neonates, data examining platelet reactivity are scarce, with platelets from preterm offsprings of PIH-pregnancies displaying lower platelet adhesion on cone and platelet analyzer (CPA) [15].

In this study we hypothesized that IUGR neonates have a distinct platelet function, possibly affecting bleeding parameters and subsequent thrombotic risk. Thus, we aimed to examine platelet responsiveness using PFA-100 in this group of neonates and associate our results with several perinatal parameters.

\section{Materials And Methods}

This is a prospective cohort study of full-term and preterm IUGR neonates born at Aretaieio Hospital, National and Kapodistrian University of Athens, during a 2-year study period (January 2017-December 2018). The Hospital Ethics Review Committee approved the study and mothers signed an informed consent prior to recruitment. Seventy-four (74) IUGR neonates, 48 full-term (> 37 weeks' gestation) and 26 preterm neonates (<37 weeks' gestation) were included. Control group consisted of 118 AGA neonates that were previously published by our research team [19].

Demographic data and perinatal parameters were listed from the maternal and neonatal medical records and are summarized in Table 1. Neonates were monitored till discharge and any postnatal complication was recorded. IUGR group included neonates with a prenatal diagnosis of estimated fetal weight (EFW) $<10$ th centile and a distinct IUGR causative pattern. The AUDIPOG computer-generated program was used to calculate the customized percentile for each pregnancy. Normal birth weight (BW) percentile limits were adjusted using significant determinants of BW (maternal age, height and weight, GA, parity and gender). (https://www.audipog.net/Estimation-croissance) Intrauterine follow up of IUGR fetuses included repeated Doppler studies assessing the pulsatility index $(\mathrm{PI})$ of the uterine, umbilical, and cerebral arteries. In 22 cases PI values were in the upper limits for the corresponding GA indicating compromised fetal perfusion $[20,21]$. Additionally, the cephalization index (CI) (ratio of head 
circumference to body weight) [22] and $\mathrm{HC} / \mathrm{AC}$ ratio were also used as measures of fetal compromise [23]. Exclusion criteria included cord blood Hct $<35 \%$, cord blood platelet count $<100.000 / \mathrm{mL}$, hypothermia $<35^{\circ} \mathrm{C}$ or any major chromosomal anomaly. 
Table 1

Demographic data, perinatal parameters and CTs of control, IUGR, term IUGR and preterm IUGR neonates

\begin{tabular}{|c|c|c|c|c|c|c|}
\hline VARIABLE & CONTROL & IUGR & $\begin{array}{l}p \\
\text { value }\end{array}$ & $\begin{array}{l}\text { TERM } \\
\text { IUGR }\end{array}$ & $\begin{array}{l}\text { PRETERM } \\
\text { IUGR }\end{array}$ & $\begin{array}{l}p \\
\text { value }\end{array}$ \\
\hline $\mathbf{N}$ & 118 & 74 & & 48 & 26 & \\
\hline COL/EPI CTs (sec) & $\begin{array}{l}112.5(93- \\
145)\end{array}$ & $132(95-181)$ & 0.04 & $\begin{array}{l}126(90- \\
157)\end{array}$ & $\begin{array}{l}137(104- \\
203)\end{array}$ & 0.001 \\
\hline $\begin{array}{l}\text { COL/ADP CTs } \\
\text { (sec) }\end{array}$ & $72(64-80)$ & $73(65-80)$ & 0.55 & $70(62-80)$ & $75(68-82)$ & 0.08 \\
\hline GA (weeks) & $\begin{array}{l}39^{+1}\left(38^{+2}\right. \\
\left.39^{+6}\right)\end{array}$ & $\begin{array}{l}37^{+6}\left(36^{+1}\right. \\
\left.39^{+3}\right)\end{array}$ & $<0.001$ & $\begin{array}{l}39^{+2}(38 \\
\left.-39^{+4}\right)\end{array}$ & $\begin{array}{l}35^{+4}\left(34^{+1}\right. \\
\left.-36^{+2}\right)\end{array}$ & $<0.001$ \\
\hline Preterm delivery & 12 & 35 & $<0.001$ & N/A & N/A & N/A \\
\hline BW (grams) & $\begin{array}{l}3305(3080- \\
3560)\end{array}$ & $\begin{array}{l}2510(2080- \\
2740)\end{array}$ & $<0.001$ & $\begin{array}{l}2670 \\
(2510 \\
-2810)\end{array}$ & $\begin{array}{l}1895(1700 \\
-2190)\end{array}$ & $<0.001$ \\
\hline BW centile & $\begin{array}{l}50.0(35.0 \\
-69.0)\end{array}$ & $5.0(2.0-8.0)$ & $<0.001$ & $\begin{array}{l}6.0(4.5 \\
-8.0)\end{array}$ & $\begin{array}{l}2.0(2.0 \\
-5.0)\end{array}$ & $<0.001$ \\
\hline Gender: female & 47 & 54 & 0.32 & 48 & 65 & 0.15 \\
\hline IVF & 5 & 12 & 0.08 & 6 & 23 & 0.03 \\
\hline CS & 66 & 78 & 0.07 & 69 & 96 & 0.006 \\
\hline T at birth $\left({ }^{\circ} \mathrm{C}\right)$ & $\begin{array}{l}36.3(36.1 \\
-36.6)\end{array}$ & $\begin{array}{l}36.10 \\
(35.90- \\
36.40)\end{array}$ & 0.007 & $\begin{array}{l}36.2(36.0 \\
-36.4)\end{array}$ & $\begin{array}{l}36.0(35.8 \\
-36.5)\end{array}$ & 0.0767 \\
\hline APGAR 1': <5 & 0 & 1 & \multirow[t]{3}{*}{0.04} & 0 & 4 & \multirow[t]{3}{*}{0.02} \\
\hline APGAR 1': 5-7 & 0 & 4 & & 0 & 12 & \\
\hline APGAR 1': 8-10 & 100 & 95 & & 100 & 85 & \\
\hline APGAR 5':8-10 & 100 & 100 & N/A & 100 & 100 & N/A \\
\hline $\begin{array}{l}\text { Neonatal Blood } \\
\text { group: } 0\end{array}$ & 39 & 36 & 0.73 & 35 & 38 & 0.80 \\
\hline $\begin{array}{l}\text { Neonatal WBC } \\
\left(\times 10^{9} / \mathrm{L}\right)\end{array}$ & $\begin{array}{l}13.2(11.4 \\
-15.2)\end{array}$ & $\begin{array}{l}11.4(9.54- \\
13.5)\end{array}$ & $<0.001$ & $\begin{array}{l}12.8(10.7 \\
-14.6)\end{array}$ & $\begin{array}{l}9.57(7.02 \\
-11.1)\end{array}$ & 0.38 \\
\hline
\end{tabular}

Arithmetic data are shown as median values (25th -75 th pctl). Categorical characteristics are presented as percentages.

CT: closure time, GA: Gestational age, BW: Birthweight, IVF: in vitro fertilization, CS: caesarian section, T: temperature, LMWH: low molecular weight heparin, PIH: pregnancy-induced hypertension, HC: head circumference, AC: abdominal circumference, $\mathrm{Cl}$ : cephalization index 


\begin{tabular}{|c|c|c|c|c|c|c|}
\hline VARIABLE & CONTROL & IUGR & value & $\begin{array}{l}\text { TERM } \\
\text { IUGR }\end{array}$ & $\begin{array}{l}\text { PRETERM } \\
\text { IUGR }\end{array}$ & value \\
\hline Neonatal Hb (g/dl) & $\begin{array}{l}15.15(14.4 \\
-16.05)\end{array}$ & $\begin{array}{l}16.10 \\
(15.10- \\
17.00)\end{array}$ & $<0.001$ & $\begin{array}{l}16.1(15.1 \\
-17.5)\end{array}$ & $\begin{array}{l}16.2(15.0 \\
-16.9)\end{array}$ & 0.54 \\
\hline Neonatal Hct (\%) & $\begin{array}{l}45.1(42.2 \\
-47.75)\end{array}$ & $\begin{array}{l}48.00 \\
(45.00- \\
50.80)\end{array}$ & $<0.001$ & $\begin{array}{l}48.0(45.0 \\
-53.0)\end{array}$ & $\begin{array}{l}48.0(44.7 \\
-50.0)\end{array}$ & 0.58 \\
\hline $\begin{array}{l}\text { Neonatal PLT } \\
\left(\times 10^{9} / \mathrm{L}\right)\end{array}$ & $\begin{array}{l}251.0(207.5 \\
-296.0)\end{array}$ & $\begin{array}{l}243.0(187.0- \\
283.0)\end{array}$ & 0.16 & $\begin{array}{l}248.0 \\
(187.0 \\
-291.0)\end{array}$ & $\begin{array}{l}233.5 \\
(192.0 \\
-277.0)\end{array}$ & 0.47 \\
\hline Neonatal MPV (fL) & $\begin{array}{l}9.8(8.4 \\
-10.5)\end{array}$ & $\begin{array}{l}9.70(8.00- \\
10.40)\end{array}$ & 0.59 & $\begin{array}{l}9.9(8.2 \\
-10.5)\end{array}$ & $\begin{array}{l}8.8(7.6 \\
-10.0)\end{array}$ & 0.11 \\
\hline Aspirin: no & 92 & 80 & 0.04 & 81 & 77 & $<0.001$ \\
\hline $\begin{array}{l}\text { Aspirin: }<7 \text { days } \\
\text { before labor }\end{array}$ & 2 & 8 & & 0 & 23 & \\
\hline $\begin{array}{l}\text { Aspirin: }>7 \text { days } \\
\text { before labor }\end{array}$ & 7 & 12 & & 19 & 0 & \\
\hline LMWH & 8 & 14 & 0.27 & 8 & 23 & 0.08 \\
\hline $\begin{array}{l}\text { Epidural } \\
\text { anesthesia }\end{array}$ & 75 & 80 & 0.49 & 75 & 88 & 0.17 \\
\hline $\begin{array}{l}\text { General } \\
\text { anesthesia }\end{array}$ & 1 & 5 & 0.05 & 4 & 8 & 0.52 \\
\hline $\begin{array}{l}\text { Pethidine } \\
\text { peripartum }\end{array}$ & 4 & 1 & 0.27 & 2 & 0 & 0.45 \\
\hline $\begin{array}{l}\text { Ampicillin } \\
\text { peripartum }\end{array}$ & 10 & 7 & 0.42 & 8 & 4 & 0.46 \\
\hline Hypothyroidism & 14 & 22 & 0.16 & 12 & 38 & 0.01 \\
\hline Smoking & $\mathrm{N} / \mathrm{A}$ & 23 & $\mathrm{~N} / \mathrm{A}$ & 21 & 27 & 0.55 \\
\hline PIH/preeclampsia & $\mathrm{N} / \mathrm{A}$ & 9 & $\mathrm{~N} / \mathrm{A}$ & 8 & 12 & 0.65 \\
\hline Thrombophilia & $\mathrm{N} / \mathrm{A}$ & 7 & $\mathrm{~N} / \mathrm{A}$ & 8 & 4 & 0.49 \\
\hline $\mathrm{HC}(\mathrm{cm})$ & $\mathrm{N} / \mathrm{A}$ & $\begin{array}{l}32.70 \\
(31.50- \\
34.00)\end{array}$ & $\mathrm{N} / \mathrm{A}$ & $\begin{array}{l}33.6(32.5 \\
-34.3)\end{array}$ & $\begin{array}{l}31.2(29.7 \\
-32.0)\end{array}$ & $<0.001$ \\
\hline \multicolumn{7}{|c|}{$\begin{array}{l}\text { Arithmetic data are shown as median values ( } 25 \text { th }-75 \text { th } \mathrm{pctl} \text { ). Categorical characteristics are } \\
\text { presented as percentages. }\end{array}$} \\
\hline \multicolumn{7}{|c|}{$\begin{array}{l}\text { CT: closure time, GA: Gestational age, BW: Birthweight, IVF: in vitro fertilization, CS: caesarian section, } \\
\text { T: temperature, LMWH: Iow molecular weight heparin, PIH: pregnancy-induced hypertension, HC: head } \\
\text { circumference, AC: abdominal circumference, Cl: cephalization index }\end{array}$} \\
\hline
\end{tabular}




\begin{tabular}{|c|c|c|c|c|c|c|}
\hline VARIABLE & CONTROL & IUGR & $p_{\text {value }}$ & $\begin{array}{l}\text { TERM } \\
\text { IUGR }\end{array}$ & $\begin{array}{l}\text { PRETERM } \\
\text { IUGR }\end{array}$ & $\mathrm{p}_{\text {value }}$ \\
\hline $\mathrm{AC}(\mathrm{cm})$ & $\mathrm{N} / \mathrm{A}$ & $\begin{array}{l}28.25 \\
(26.10- \\
29.50)\end{array}$ & $\mathrm{N} / \mathrm{A}$ & $\begin{array}{l}28.9(27.5- \\
30.5)\end{array}$ & $\begin{array}{l}26.0(25.0 \\
-27.5)\end{array}$ & $<0.001$ \\
\hline $\mathrm{Cl}$ & $\mathrm{N} / \mathrm{A}$ & $\begin{array}{l}1.30(1.24- \\
1.51)\end{array}$ & $\mathrm{N} / \mathrm{A}$ & $\begin{array}{l}1.3(1.2 \\
-1.3)\end{array}$ & $\begin{array}{l}1.6(1.5 \\
-1.8)\end{array}$ & $<0.001$ \\
\hline $\mathrm{HC} / \mathrm{AC}$ & $\mathrm{N} / \mathrm{A}$ & $\begin{array}{l}1.15(1.11- \\
1.21)\end{array}$ & N/A & $\begin{array}{l}1.1(1.1 \\
-1.2)\end{array}$ & $\begin{array}{l}1.2(1.1 \\
-1.2)\end{array}$ & 0.26 \\
\hline \multicolumn{7}{|c|}{$\begin{array}{l}\text { Arithmetic data are shown as median values ( } 25 \text { th }-75 \text { th } \mathrm{pctl} \text { ). Categorical characteristics are } \\
\text { presented as percentages. }\end{array}$} \\
\hline \multicolumn{7}{|c|}{$\begin{array}{l}\text { CT: closure time, GA: Gestational age, BW: Birthweight, IVF: in vitro fertilization, CS: caesarian section, } \\
\text { T: temperature, LMWH: low molecular weight heparin, PIH: pregnancy-induced hypertension, HC: head } \\
\text { circumference, AC: abdominal circumference, Cl: cephalization index }\end{array}$} \\
\hline
\end{tabular}

Umbilical cord samples were tested via PFA-100® - Platelet Function Analyzer (DADE BEHRING) according to manufacturer' $s$ instructions as previously described $[24,25]$. PFA-100 is a cartridge system of in vitro assessment of primary, platelet-related hemostasis that is sensitive to different hemostatic defects, medication effects, platelet deficiencies and hematocrit disturbances [24, 26]. Closure times (CTs) for both stimulating agents collagen and epinephrine (COL/EPI) or adenosine 5'-phosphate (COL/ADP) were determined. Additional tests included the Complete Blood Count (CBC) (Abbott cell-dyn 3700 hematology analyzer) and blood group. Platelet count was confirmed by microscopic evaluation of peripheral blood smears.

Statistical analysis was performed by SAS 9.4 for Windows (SAS Institute Inc. NC, USA) [27]. For differences of data expressed in a numeric form, the Kruskal-Wallis test was performed, while comparisons or proportions of qualitative data (Normal/Abnormal or Yes/No values) were performed via the chi-square test. Odds ratios were evaluated via the Wald's $\mathrm{p}$-value. The statistical significance level was set to 0.05 and all tests were two tailed.

\section{Results}

COL/EPI and COL/ADP CTs were compared between IUGR and AGA neonates. COL/EPI CTs were prolonged in IUGR neonates (median 132s) compared to control neonates (median 112,5s), $p=0.04$. No differences were found for COL/ADP CTs, as shown on Table 1 and Figure 1. Further analysis between control and IUGR neonates showed that IUGR neonates were characterized by lower BW $(p<0.001)$, BW centile $(p<0.001), G A(p<0.001)$, temperature at birth $(p=0.007)$ and Apgar score at 1 st minute $(p=0.04)$. A higher percentage of pregnant women of IUGR fetuses received aspirin prophylaxis compared to control fetuses $(p=0.04)$. IUGR neonates had lower median WBCs count $(p<0.001)$, higher $\mathrm{Hb}(p<0.001)$ and higher Hct $(p<0.001)$. Median platelet count in IUGR newborns was $243 \times 10^{9} / \mathrm{L}$, lower than the average platelet count in the control group $251 \times 10^{9} / \mathrm{L}$, although not statistically significant. 
Additionally, differences between term $(\mathrm{N}=48)$ and preterm $(\mathrm{N}=24)$ neonates among the group of IUGR neonates were tested. According to our results COL/EPI CT ranges for term and preterm IUGR neonates were $90-157$ s and 104-203s respectively, and accordingly COL/ADP ranges were 62-80s (term) and 6882s (preterm) (Table 1). Difference was found only in COL/EPI CT ( $p=0.001)$. (Figure 2) Moreover, preterm IUGR neonates had lower median BW( $p<0.001)$, BW centile $(p<0.001)$, Apgar score at 1 st minute $(p=0.02)$, median $\mathrm{HC}(p<0.001)$, median $\mathrm{AC}(\mathrm{p}<0.001)$ and higher $\mathrm{Cl}(\mathrm{p}<0.001)$ compared to term IUGR neonates. $A$ higher percentage of in vitro fertilization (IVF) $(p=0.03)$, caesarian section (CS) $(p=0.006)$, aspirin $(p<0.001)$ and levothyroxine administration $(p=0.01)$ were observed among mothers of preterm IUGR neonates. (Table 1)

A mixed model to control the effects of maternal aspirin administration in neonatal COL/EPI and COL/ADP CTs was implemented. Results showed that aspirin administration had no effect in COL/EPI or COL/ADP CTs neither in the complete population, nor in the IUGR or control group, nor when adjusting for term and preterm neonates ( $p>0.05$ in all cases). The same results were obtained when aspirin administration was grouped into $<7$ or $>7$ days from delivery. Furthermore, a multivariate linear regression model was applied in order to identify factors that could affect both CTs in the whole group of IUGR neonates. The statistically important parameter for COL/EPI CT was delivery time (with preterm neonates exhibiting prolonged COL/EPI CTs, $\mathrm{p}=0.05$ ). As far as COL/ADP CT is concerned, no parameter showed statistical significance.

Finally, we evaluatedCOL/EPI and COL/ADP CT values in accordance with different parameters in the group of IUGR neonates. COL/ADP CTs were shorter in IUGR neonates born via vaginal delivery, compared to those born via CS [62s (60s-75s) vs 74s (67s-86s), $(\mathrm{p}=0.007)]$. COL/ADP CTs were prolonged in IUGR neonates whose mothers had received epidural anesthesia, compared to other methods of anesthesia [73s (67s-86s) vs 62s (59s-75s), ( $(\mathrm{p}=0.03)]$. COL/ADP CTs were shorter after intrapartum antibiotic prophylaxis (IAP) with ampicillin compared to no antibiotics [59s (57s-60s) vs 74s (66s-82s), $(p=0.005)$ ]. $\mathrm{COL/EPI} \mathrm{and} \mathrm{COL/ADP} \mathrm{CTs} \mathrm{observed} \mathrm{for} \mathrm{each} \mathrm{different} \mathrm{cause} \mathrm{of} \mathrm{IUGR} \mathrm{are} \mathrm{depicted} \mathrm{in} \mathrm{Table} \mathrm{2.} \mathrm{The}$ specific cause of IUGR seems to have no impact on CTs ( $p>0.05$ in all cases). As expected, COL/EPI CTs and COL/ADP CTs had positive correlation $(r=0.37, p<0.001)$. No correlation was proved between COL/EPI and COL/ADP CTs and hematological parameters in IUGR neonates. 
Table 2

Neonatal COL/EPI and COL/ADP CTs values as Median (IQR) with regard to the cause of IUGR.

\begin{tabular}{|c|c|c|c|c|c|}
\hline IUGR cause & & COL/EPI CT (sec) & $p$ value & COL/ADP CT (sec) & $p$ value \\
\hline \multirow[t]{2}{*}{ Thrombophilia } & No & 132(94-182) & \multirow[t]{2}{*}{0.62} & $73(65-82)$ & \multirow[t]{2}{*}{0.39} \\
\hline & Yes & $156(106-177)$ & & $74(60-76)$ & \\
\hline \multirow[t]{2}{*}{ Hypothyroidism } & No & 135(94-177) & \multirow[t]{2}{*}{1.00} & $73(63-82)$ & \multirow[t]{2}{*}{0.82} \\
\hline & Yes & 122(101-193) & & $73(68-80)$ & \\
\hline \multirow[t]{2}{*}{ Smoking } & No & 132(98-184) & \multirow[t]{2}{*}{0.45} & $73(66-84)$ & \multirow[t]{2}{*}{0.49} \\
\hline & Yes & 118(93-161) & & $73(64-77)$ & \\
\hline \multirow[t]{2}{*}{$\mathrm{PIH} /$ preeclampsia } & No & 132(95-184) & \multirow[t]{2}{*}{0.42} & $73(65-82)$ & \multirow[t]{2}{*}{0.18} \\
\hline & Yes & 127(94-154) & & $68(57-77)$ & \\
\hline
\end{tabular}

\section{Discussion}

IUGR neonates confront great risk of perinatal morbidities and thus platelet related primary hemostasis needs to be carefully evaluated. To the best of our knowledge, our cohort represents a study of platelet function by PFA -100 in the largest number of well-defined IUGR neonates $(n=74)$ reported so far. In order to make reasonable interpretation, all data and laboratory findings were compared to a control group of 118 healthy neonates. Additionally, the comparison of special aspects between preterm and term IUGR neonates highlights important characteristics of prematurity, as preterm neonates encounter for $35 \%$ of IUGR neonates. The impact of several parameters during pregnancy and delivery of an IUGR fetus on platelet function was also tested.

According to our study lower BW and BW centile define IUGR neonate. The higher rate of preterm births in IUGR neonates is reasonable, as the risk of prematurity in IUGR is 3-fold greater than in AGA infants [28]. The well-known risk of IUGR infants for irregular thermoregulation [29] explains the lower temperature observed in IUGR group. IUGR infants have greater risk of perinatal stress due to a sentinel event superimposed on chronic fetal hypoxia from placental insufficiency [3] and this explains lower Apgar scores in IUGR newborns, as in our study.

As expected, preterm neonates had lower somatometric parameters (BW, BW centile, AC and HC). Furthermore, higher $\mathrm{Cl}$ and lower Apgar scores reflect the greater compromise of prematurity. A higher percentage of preterm births was observed in pregnancies conceived by IVF, in accordance with current literature [30]. Although there is no consensus in the optimal delivery method for a preterm birth, even in IUGR fetuses, our institution's practice favors CS as depicted with the higher percentage of preterm 
neonates born via CS [31,32]. The higher incidence of preterm labor in pregnant women with hypothyroidism despite levothyroxine replacement therapy [33], supports higher percentage of preterm birth in our group of IUGR neonates.

Regarding platelet function in our cohort study, COL/EPI CTs were prolonged in IUGR compared to control neonates, whereas no corresponding difference was found for COL/ADP CTs. According to the helpful algorithm proposed by Favaloro [34], prolonged COL/EPI CTs with normal COL/ADP CTs could be attributed to drug effect, low Hct, mild thrombocytopenia and mild platelet/von Willebrand factor (VWF) dysfunction. Aspirin is well known to prolong COL/EPI CT, when COL/ADP CT is usually normal [26]. It is worth noticing that $20 \%$ of mothers of our IUGR neonates received aspirin during pregnancy, in contrast to $8 \%$ of mothers of control newborns. This finding complies with the recommendation of low-dose aspirin prophylaxis, initiated before 16 weeks gestation for women at high risk of preeclampsia [35]. Subanalysis and linear regression model analysis support that aspirin administration during pregnancy had no effect on COL/EPI or COL/ADP CTs, neither in the complete population nor in the IUGR or control group. A small amount of acetylsalicylic acid reaches fetal circulation [36] and results in reduced levels of thromboxane $B_{2}$ in umbilical cord $[37,38]$ but, according to our findings and previous platelet aggregation studies, neonatal platelet function does not appear to be affected [39, 40].

It has been shown that lower Hct is correlated with prolongation of COL/EPI CTs [34], while higher neonatal Hct seems to explain shorter bleeding time (BT) and CTs compared to adults, partly by rheologic effects [41]. IUGR neonates in our study were characterized by higher $\mathrm{Hb}$ and $\mathrm{Hct}$ as polycythemia is common in IUGR neonates (up to 50\%) [42]. IUGR fetuses are subjected to relative hypoxia [43] that likely triggers red cell production [44-47]. Thus, the prolongation of COL/EPI CTs among IUGR neonates of the present study could not be attributed to Hct effect. In fact, we could assume that higher Hct of IUGR neonates could not compensate platelets' impaired activation.

Low platelet counts were correlated with prolongation of CTs and should be taken into consideration when interpret CTs $[24,48,49]$. For this purpose, a cut-off value of $100 \times 10^{9} / \mathrm{L}$ was set for our study group. It is well known that the incidence of thrombocytopenia in IUGR neonates is higher $[7,8]$ and is more prominent as the severity of IUGR increases [7,9-11]. However, the median platelet count of our IUGR group $\left(243 \times 10^{9} / \mathrm{L}\right)$, which is in accordance with previous reports [9], did not differ significantly from the corresponding of our control group $\left(251 \times 10^{9} / \mathrm{L}\right)$, so we could not assume that thrombocytopenia of IUGR neonates explains the observed prolongation of COL/EPI CTs.

Prolongation of COL/EPI CT of IUGR neonates seems to be the result of platelet dysfunction, although this remains a field of further investigation for this group of neonates as the majority of studies concerning platelets' activation in IUGR neonates were conducted on the subpopulation of neonates born to mothers with PIH. A study of CPA reports lower platelet adhesion in IUGR infants [15] and another study supports that preeclampsia influences the expression of GPs on activated neonatal platelet-surface which may affect platelet function, leading to an additional bleeding risk in thrombocytopenic neonates [16]. A study showed that platelets of neonates of preeclamptic mothers had a markedly higher 
responsiveness to agonists in vitro by flow cytometry, however resting platelets of IUGR neonates seemed to be in a slightly lower state of activation [50]. Prolongation of COL/EPI CT in the present study supports the impaired platelet function of IUGR neonates reported from previous studies $[15,16,50]$. It is of great importance that platelet hyporesponsiveness seems to apply for the whole group of IUGR neonates irrespective of the cause.

As far as white blood cell count is concerned, neutropenia is frequent in offsprings of pregnancies complicated with PIH $[46,51]$. IUGR neonates of our study were also characterized by lower median values of total leucocyte count compared to control group. However, leucocytes do not have any influence on CTs $[52,53]$.

Regarding the role of prematurity in our IUGR group, COL/EPI CT of preterm IUGR neonates was prolonged compared to term IUGR ones. COL/ADP CT of preterm IUGR neonates was also prolonged but not significantly. Multivariate linear regression analysis supported that prematurity affects COL/EPI CT whereas no corresponding relation was found for COL/ADP CT. Concerning low-dose aspirin administration, despite the fact that more preterm IUGR neonates were exposed in utero to aspirin, our subanalysis supports that aspirin administration during pregnancy had no effect on COL/EPI or COL/ADP CTs as previously mentioned. Preterm and term IUGR neonates did not differ in any hematological parameter (Table 1) so we could not speculate that differences in Hct or platelet count are responsible for the prolongation of COL/EPI CT. Prematurity is a well-known factor affecting platelet responsiveness. Preterm neonates have prolonged BTs [54], decreased platelet reactivity on flow cytometry studies [55], decreased platelet adhesion on CPA [56, 57], prolonged COL/EPI CT [19] or prolonged COL/ADP CT [58] on PFA-100 and lower MCF on ROTEM [59]. The available evidence suggests that the platelet hyporeactivity is less well compensated by other factors, such as high Hct, in preterm compared with full-term neonates. Thus, the present study highlights that platelet dysfunction that accompanies prematurity applies also in IUGR neonates. This was also reported in offsprings of pregnancies complicated by PIH with evidence of lower platelet adhesion on CPA, meaning impaired platelet function [15].

The observation that the difference in responsiveness between platelets of IUGR and control neonates is apparent to some agonists (epinephrine) rather than others (ADP) raises several questions concerning neonatal platelet function. An increase in the available erythrocyte ADP caused by the higher Hct in IUGR neonates may compensate for the decreased ADP secretion from neonatal platelets and explains the lack of difference in COL/ADP CTs [41]. Furthermore, a flow cytometry study showed that platelets of neonates of preeclamptic mothers had markedly higher responsiveness to ADP as agonist, after in vitro activation [50].

It is worth noticing that COL/ADP CTs were found to be shorter in IUGR neonates delivered via vaginal delivery and this could be attributed to the stimulant effect of cytokines which are expressed in higher levels in vaginal deliveries [60-62]. Both IL-6and IL-1 $\beta$ induce platelet activation and aggregation through several mechanisms [63-67]. 
As far as the role of anesthesia is concerned, COL/ADP CTs were prolonged in our IUGR neonates whose mothers received epidural anesthesia during labor. Opioids seem to have no adverse effect on platelet activation and aggregation. On the other hand, ADP-induced platelet aggregation decreases with bupivacaine [68], Platelet-Activating Factor (PAF) concentrations decrease with lignocaine [69] and platelet aggregation is inhibited by ropivacaine via PFA-100 [70].

Although previous studies support that ampicillin inhibits ADP-induced platelet aggregation in adults [71, 72], VLBW neonates [73] and NICU patients [74] via several mechanisms [75], the contrary was reported in our study. A possible explanation could be the small number of neonates whose mothers received ampicillin peripartum (5 out of 74). Moreover, IUGR neonates of our study did not have any evidence of bacterial infection as opposed to neonates receiving ampicillin in previous studies $[73,74]$.

Present study presents some limitations. There were no matching venous samples to cord blood samples as our policy was not to perform unnecessary tests. Moreover, results should be interpreted in a larger number of neonates.

In conclusion, the present study supports that IUGR neonates could be at a greater risk for bleeding tendency, as indicated by the observed impaired platelet function. This platelet hyporesponsiveness is overexpressed in preterm IUGR neonates, a group that confronts mostly the risk of intraventricular and pulmonary hemorrhage. In clinical practice, the evaluation of cord blood CTs could have a prospective character; cord blood samples offer the advantage of collecting larger blood volumes and perform several tests (ie. blood gases, blood group, PFA -100), avoiding frequent neonatal blood sampling, a leading cause of anemia of the newborn. An abnormal CT value in a high-risk neonate could warn for closer evaluation and proper management during the first days of their lives. The accurate reading of the results could play an important role both in the prevention and treatment of hemorrhagic complications and in the establishment of transfusion guidelines.

\section{Abbreviations}

AC: Abdominal circumference

ADP: Adenosine diphosphate

AGA: Appropriate for gestational age

BT: Bleeding time

BW: Birthweight

CBC: Complete blood count

Cl: Cephalization index

CPA: Cone and platelet analyzer 
CS: Caesarian section

CT: Closure time

EFW: Estimated fetal weight

GA: Gestational age

HC: Head circumference

IAP: Intrapartum antibiotic prophylaxis

IUGR: Intrauterine Growth Restriction

IVF: In vitro fertilization

MCF: Maximal clot firmness

NICU: Neonatal intensive care unit

PAF: Platelet activating factor

PFA: Platelet function analyzer

PI: Pulsatility index

PIH: Pregnancy induced hypertension

TEM: Thromboelastometry

VLBW: Very low birthweight

\section{Declarations}

Funding: No funding was received for conducting this study.

Conflicts of interest/Competing interests: The authors have no competing interests to declare that are relevant to the content of this article.

Availability of data and material: Available data on request.

Code availability: Not applicable

Authors' contributions: Dr Kollia collected data and analyzed data, wrote the initial draft of manuscript, reviewed and revised the manuscript. Profs lacovidou, Valsami, Politou and Boutsikou conceptualized and designed the study, coordinated and supervised data collection, analyzed data, revised the initial draft manuscript, reviewed and revised the manuscript. Prof Iliodromiti and Dr Sokou critically reviewed 
the manuscript for important intellectual content. Dr Mougiou collected data and reviewed the manuscript. Drs Pouliakis and Boutsikou carried out statistical analyses. All authors approved the final manuscript as submitted and agree to be accountable for all aspects of the work

Ethics approval: This study was performed in line with the principles of the Declaration of Helsinki. Approval was granted by the Ethics Committee of Aretaieio Hospital, National and Kapodistrian University of Athens (31.01.2017).

Consent to participate: Mothers signed an informed consent prior to recruitment.

Consent for publication: Not applicable

\section{References}

1. Mandruzzato, G., Antsaklis, A., Botet, F., Chervenak, F. A., Figueras, F., Grunebaum, A., Puerto, B., Skupski, D., Stanojevic, M., \& WAPM (2008). Intrauterine restriction (IUGR). Journal of perinatal medicine, 36(4), 277-281. https://doi.org/10.1515/JPM.2008.050

2. Sharma, D., Shastri, S., Farahbakhsh, N., \& Sharma, P. (2016). Intrauterine growth restriction part 1. The journal of maternal-fetal \& neonatal medicine : the official journal of the European Association of Perinatal Medicine, the Federation of Asia and Oceania Perinatal Societies, the International Society of PerinatalObstetricians, 29(24), 3977-3987. https://doi.org/10.3109/14767058.2016.1152249

3. Kesavan, K., \& Devaskar, S. U. (2019). Intrauterine Growth Restriction: Postnatal Monitoring and Outcomes. Pediatricclinicsof North America, 66(2), 403-423. https://doi.org/10.1016/j.pcl.2018.12.009

4. Nardozza, L. M., Caetano, A. C., Zamarian, A. C., Mazzola, J. B., Silva, C. P., Marçal, V. M., Lobo, T. F., Peixoto, A. B., \& Araujo Júnior, E. (2017). Fetal growth restriction: current knowledge. Archives of gynecology and obstetrics, 295(5), 1061-1077. https://doi.org/10.1007/s00404-017-4341-9

5. Sharma, D., Shastri, S., \& Sharma, P. (2016). Intrauterine Growth Restriction: Antenatal and Postnatal Aspects. Clinical medicine insights. Pediatrics, 10, 67-83. https://doi.org/10.4137/CMPed.S40070

6. Rosenberg A. (2008). The IUGR newborn. Seminars in perinatology, 32(3), 219-224. https://doi.org/10.1053/j.semperi.2007.11.003

7. Christensen, R. D., Baer, V. L., Henry, E., Snow, G. L., Butler, A., \& Sola-Visner, M. C. (2015). Thrombocytopenia in Small-for-Gestational-Age Infants. Pediatrics, 136(2), e361-e370. https://doi.org/10.1542/peds.2014-4182

8. Fustolo-Gunnink, S. F., Vlug, R. D., Smits-Wintjens, V. E., Heckman, E. J., Te Pas, A. B., Fijnvandraat, K., \& Lopriore, E. (2016). Early-Onset Thrombocytopenia in Small-For-Gestational-Age 
Neonates: A Retrospective Cohort Study. PloS one, 11(5), e0154853.

https://doi.org/10.1371/journal.pone.0154853

9. Wasiluk, A., Dabrowska, M., Osada, J., Jasinska, E., Laudanski, T., \& Redzko, S. (2011). Platelet indices in SGA newborns. Advances in medical sciences, 56(2), 361-365.

https://doi.org/10.2478/v10039-011-0030-2

10. Tsao, P. N., Teng, R. J., Chou, H. C., \& Tsou, K. I. (2002). The thrombopoietin level in the cord blood in premature infants born to mothers with pregnancy-induced hypertension. Biology of the neonate, 82(4), 217-221. https://doi.org/10.1159/000065888

11. Kannar Vidyavathi, Deepthi A, Harendra Kumar Malligere Lingaiah, Junjegowda Krishnappa, Mariyappa Narayanaswamy (2014) Effect of gestational age, prematurity and birth asphyxia on platelet indices in neonates. Journal of Clinical Neonatology. 3(3): p. 144-147.

12. Maruyama, H., Shinozuka, M., Kondoh, Y., Akahori, Y., Matsuda, M., Inoue, S., Sumida, Y., \& Morishima, T. (2008). Thrombocytopenia in preterm infants with intrauterine growth restriction. Acta medica Okayama, 62(5), 313-317. https://doi.org/10.18926/AMO/30973

13. Litt, J. S., \& Hecht, J. L. (2014). Placental pathology and neonatal thrombocytopenia: lesion type is associated with increased risk. Journal of perinatology : official journal of the California Perinatal Association, 34(12), 914-916. https://doi.org/10.1038/jp.2014.117

14. Meberg, A., Jakobsen, E., \& Halvorsen, K. (1982). Humoral regulation of erythropoiesis and thrombopoiesis in appropriate and small for gestational age infants. Acta paediatrica Scandinavica, 71(5), 769-773. https://doi.org/10.1111/j.1651-2227.1982.tb09517.x

15. Strauss, T., Maayan-Metzger, A., Simchen, M. J., Morag, I., Shenkmean, B., Kuint, J., \& Kenet, G. (2010). Impaired platelet function in neonates born to mothers with diabetes or hypertension during pregnancy. Klinische Padiatrie, 222(3), 154-157. https://doi.org/10.1055/s-0030-1249092

16. Kühne, T., Ryan, G., Blanchette, V., Semple, J. W., Hornstein, A., Mody, M., Chang, W., McWhirter, L., \& Freedman, J. (1996). Platelet-surface glycoproteins in healthy and preeclamptic mothers and their newborn infants. Pediatric research, 40(6), 876-880. https://doi.org/10.1203/00006450-19961200000018

17. Kazmi, R. S., Cooper, A. J., \& Lwaleed, B. A. (2011). Platelet function in pre-eclampsia. Seminars in thrombosis and hemostasis, 37(2), 131-136. https://doi.org/10.1055/s-0030-1270339

18. Sokou, R., Konstantinidi, A., Stefanaki, C., Tsantes, A. G., Parastatidou, S., Lampropoulou, K., Katsaras, G., Tavoulari, E., lacovidou, N., Kyriakou, E., Gounaris, A., Bonovas, S., \& Tsantes, A. E. (2019). Thromboelastometry: studying hemostatic profile in small for gestational age neonates-a pilot 
observational study. European journal of pediatrics, 178(4), 551-557. https://doi.org/10.1007/s00431019-03331-w

19. Valsami, S., Kollia, M., Mougiou, V., Sokou, R., Isaakidou, E., Boutsikou, M., Pouliakis, A., Iliodromiti, Z., Carr, R., Boutsikou, T., lacovidou, N., \& Politou, M. (2020). Evaluation of PFA-100 closure times in cord blood samples of healthy term and preterm neonates. Clinical chemistry and laboratory medicine, 58(4), e113-e116. https://doi.org/10.1515/cclm-2019-0948

20. Society for Maternal-Fetal Medicine (SMFM). Electronic address: pubs@smfm.org, Martins, J. G., Biggio, J. R., \& Abuhamad, A. (2020). Society for Maternal-Fetal Medicine Consult Series \#52: Diagnosis and management of fetal growth restriction: (Replaces Clinical Guideline Number 3, April 2012). American journal of obstetrics and gynecology, 223(4), B2-B17. https://doi.org/10.1016/j.ajog.2020.05.010.

21. American College of Obstetricians and Gynecologists' Committee on Practice BulletinsObstetrics and the Society forMaternal-FetalMedicin (2019). ACOG Practice Bulletin No. 204: Fetal Growth Restriction. Obstetrics and gynecology, 133(2), e97-e109. https://doi.org/10.1097/AOG.0000000000003070

22. Harel, S., Tomer, A., Barak, Y., Binderman, I., \& Yavin, E. (1985). The cephalization index: a screening device for brain maturity and vulnerability in normal and intrauterine growth retarded newborns. Brain \& development, 7(6), 580-584. https://doi.org/10.1016/s0387-7604(85)80005-x

23. Dashe, J. S., McIntire, D. D., Lucas, M. J., \& Leveno, K. J. (2000). Effects of symmetric and asymmetric fetal growth on pregnancy outcomes. Obstetrics and gynecology, 96(3), 321-327. https://doi.org/10.1016/s0029-7844(00)00943-1

24. Kundu, S. K., Heilmann, E. J., Sio, R., Garcia, C., Davidson, R. M., \& Ostgaard, R. A. (1995). Description of an in vitro platelet function analyzer-PFA-100. Seminars in thrombosis and hemostasis, 21 Suppl 2, 106-112. https://doi.org/10.1055/s-0032-1313612

25. Rand, M. L., Carcao, M. D., \& Blanchette, V. S. (1998). Use of the PFA-100 in the assessment of primary, platelet-related hemostasis in a pediatric setting. Seminars in thrombosis and hemostasis, 24(6), 523-529. https://doi.org/10.1055/s-2007-996051

26. Favaloro E. J. (2008). Clinical utility of the PFA-100. Seminars in thrombosis and hemostasis, 34(8), 709-733. https://doi.org/10.1055/s-0029-1145254

27. DiMaggio, C., SAS for EpidemiologistsApplications and Methods. 2013: Springer.

28. Lackman, F., Capewell, V., Richardson, B., daSilva, O., \& Gagnon, R. (2001). The risks of spontaneous preterm delivery and perinatal mortality in relation to size at birth according to fetal versus 
neonatal growth standards. American journal of obstetrics and gynecology, 184(5), 946-953. https://doi.org/10.1067/mob.2001.111719

29. Doctor, B. A., O'Riordan, M. A., Kirchner, H. L., Shah, D., \& Hack, M. (2001). Perinatal correlates and neonatal outcomes of small for gestational age infants born at term gestation. American journal of obstetrics and gynecology, 185(3), 652-659. https://doi.org/10.1067/mob.2001.116749

30. Cavoretto, P., Candiani, M., Giorgione, V., Inversetti, A., Abu-Saba, M. M., Tiberio, F., Sigismondi, C., \& Farina, A. (2018). Risk of spontaneous preterm birth in singleton pregnancies conceived after IVF/ICSI treatment: meta-analysis of cohort studies. Ultrasound in obstetrics \& gynecology : the official journal of the International Society of Ultrasound in Obstetrics and Gynecology, 51(1), 43-53. https://doi.org/10.1002/uog.18930

31. Alfirevic, Z., Milan, S. J., \& Livio, S. (2012). Caesarean section versus vaginal delivery for preterm birth in singletons. The Cochrane database of systematic reviews, 6(6), CD000078. https://doi.org/10.1002/14651858.CD000078.pub2

32. Werner, E. F., Savitz, D. A., Janevic, T. M., Ehsanipoor, R. M., Thung, S. F., Funai, E. F., \& Lipkind, H. S. (2012). Mode of delivery and neonatal outcomes in preterm, small-for-gestational-age newborns. Obstetrics and gynecology, 120(3), 560-564. https://doi.org/10.1097/AOG.0b013e318265b16c.

33. Parizad Nasirkandy, M., Badfar, G., Shohani, M., Rahmati, S., YektaKooshali, M. H., Abbasalizadeh, S., Soleymani, A., \& Azami, M. (2017). The relation of maternal hypothyroidism and hypothyroxinemia during pregnancy on preterm birth: An updated systematic review and meta-analysis. International journal of reproductive biomedicine, 15(9), 543-552.

34. Favaloro, E.J. (2017) Clinical utility of closure times using the platelet function analyzer100/200. Am J Hematol, 92(4): p. 398-404.

35. ACOG Committee Opinion No. 743: Low-Dose Aspirin Use During Pregnancy. (2018). Obstetrics and gynecology, 132(1), e44-e52. https://doi.org/10.1097/AOG.0000000000002708

36. Leonhardt, A., Bernert, S., Watzer, B., Schmitz-Ziegler, G., \& Seyberth, H. W. (2003). Low-dose aspirin in pregnancy: maternal and neonatal aspirin concentrations and neonatal prostanoid formation. Pediatrics, 111(1), e77-e81. https://doi.org/10.1542/peds.111.1.e77

37. Benigni, A., Gregorini, G., Frusca, T., Chiabrando, C., Ballerini, S., Valcamonico, A., Orisio, S., Piccinelli, A., Pinciroli, V., \& Fanelli, R. (1989). Effect of low-dose aspirin on fetal and maternal generation of thromboxane by platelets in women at risk for pregnancy-induced hypertension. The New England journal of medicine, 321(6), 357-362. https://doi.org/10.1056/NEJM198908103210604

38. Parker, C. R., Jr, Hauth, J. C., Goldenberg, R. L., Cooper, R. L., \& Dubard, M. B. (2000). Umbilical cord serum levels of thromboxane B2 in term infants of women who participated in a placebo-controlled 
trial of low-dose aspirin. The Journal of maternal-fetal medicine, 9(4), 209-215.

39. Louden, K. A., Broughton Pipkin, F., Heptinstall, S., Fox, S. C., Tuohy, P., O'Callaghan, C., Mitchell, J. R., \& Symonds, E. M. (1994). Neonatal platelet reactivity and serum thromboxane B2 production in whole blood: the effect of maternal low dose aspirin. British journal of obstetrics and gynaecology, 101(3), 203208. https://doi.org/10.1111/j.1471-0528.1994.tb13110.x

40. Dasari, R., Narang, A., Vasishta, K., \& Garewal, G. (1998). Effect of maternal low dose aspirin on neonatal platelet function. Indian pediatrics, 35(6), 507-511.

41. Israels, S. J., Cheang, T., McMillan-Ward, E. M., \& Cheang, M. (2001). Evaluation of primary hemostasis in neonates with a new in vitro platelet function analyzer. The Journal of pediatrics, 138(1), 116-119. https://doi.org/10.1067/mpd.2001.109794

42. Werner E. J. (1995). Neonatal polycythemia and hyperviscosity. Clinics in perinatology, 22(3), 693-710.

43. Kingdom, J. C., \& Kaufmann, P. (1997). Oxygen and placental villous development: origins of fetal hypoxia. Placenta, 18(8), 613-626. https://doi.org/10.1016/s0143-4004(97)90000-x.

44. Philip, A. G., \& Tito, A. M. (1989). Increased nucleated red blood cell counts in small for gestational age infants with very low birth weight. American journal of diseases of children (1960), 143(2), 164-169. https://doi.org/10.1001/archpedi.1989.02150140050019.

45. Bernstein, P. S., Minior, V. K., \& Divon, M. Y. (1997). Neonatal nucleated red blood cell counts in small-for-gestational age fetuses with abnormal umbilical artery Doppler studies. American journal of obstetrics and gynecology, 177(5), 1079-1084. https://doi.org/10.1016/s0002-9378(97)70018-8

46. Koenig, J. M., \& Christensen, R. D. (1989). Incidence, neutrophil kinetics, and natural history of neonatal neutropenia associated with maternal hypertension. The New England journal of medicine, 321(9), 557-562. https://doi.org/10.1056/NEJM198908313210901

47. Rollins, M. D., Maxwell, A. P., Afrasiabi, M., Halliday, H. L., \& Lappin, T. R. (1993). Cord blood erythropoietin, $\mathrm{pH}, \mathrm{PaO} 2$ and haematocrit following caesarean section before labour. Biology of the neonate, 63(3), 147-152. https://doi.org/10.1159/000243924

48. Harrison, P., Robinson, M. S., Mackie, I. J., Joseph, J., McDonald, S. J., Liesner, R., Savidge, G. F., Pasi, J., \& Machin, S. J. (1999). Performance of the platelet function analyser PFA-100 in testing abnormalities of primary haemostasis. Blood coagulation \& fibrinolysis : an international journal in haemostasis and thrombosis, 10(1), 25-31. https://doi.org/10.1097/00001721-199901000-00004

49. Jilma B. (2001). Platelet function analyzer (PFA-100): a tool to quantify congenital or acquired platelet dysfunction. The Journal of laboratory and clinical medicine, 138(3), 152-163.

https://doi.org/10.1067/mlc.2001.117406

Page 19/23 
50. Klein, B., Faridi, A., Amo-Takyi, B. K., Heilmann, L., Von Tempelhoff, G. F., \& Rath, W. (2001). Neonatal platelet activation in preeclampsia. Clinical and applied thrombosis/hemostasis : official journal of the International Academy of Clinical and Applied Thrombosis/Hemostasis, 7(1), 29-32. https://doi.org/10.1177/107602960100700107

51. Manroe, B. L., Weinberg, A. G., Rosenfeld, C. R., \& Browne, R. (1979). The neonatal blood count in health and disease. I. Reference values for neutrophilic cells. The Journal of pediatrics, 95(1), 89-98. https://doi.org/10.1016/s0022-3476(79)80096-7

52. Roschitz, B., Sudi, K., Köstenberger, M., \& Muntean, W. (2001). Shorter PFA-100 closure times in neonates than in adults: role of red cells, white cells, platelets and von Willebrand factor. Acta paediatrica (Oslo, Norway : 1992), 90(6), 664-670.

53. Cho, Y. U., Jang, S., Park, C. J., \& Chi, H. S. (2008). Variables that affect platelet function analyzer100 (PFA-100) closure times and establishment of reference intervals in Korean adults. Annals of clinical and laboratory science, 38(3), 247-253.

54. Del Vecchio, A., Latini, G., Henry, E., \& Christensen, R. D. (2008). Template bleeding times of 240 neonates born at 24 to 41 weeks gestation. Journal of perinatology : official journal of the California Perinatal Association, 28(6), 427-431. https://doi.org/10.1038/jp.2008.1055. Sitaru, A.G., et al., Neonatal platelets from cord blood and peripheral blood. Platelets, 2005. 16(3-4): p. 203-10.

56. Linder, N., Shenkman, B., Levin, E., Sirota, L., Vishne, T. H., Tamarin, I., Dardik, R., Lubin, D., Savion, N., \& Varon, D. (2002). Deposition of whole blood platelets on extracellular matrix under flow conditions in preterm infants. Archives of disease in childhood. Fetal and neonatal edition, 86(2), F127-F130. https://doi.org/10.1136/fn.86.2.f127

57. Levy-Shraga, Y., Maayan-Metzger, A., Lubetsky, A., Shenkman, B., Kuint, J., Martinowitz, U., \& Kenet, G. (2006). Platelet function of newborns as tested by cone and plate(let) analyzer correlates with gestational Age. Acta haematologica, 115(3-4), 152-156. https://doi.org/10.1159/000090928

58. Saxonhouse, M. A., Garner, R., Mammel, L., Li, Q., Muller, K. E., Greywoode, J., Miller, C., \& SolaVisner, M. (2010). Closure times measured by the platelet function analyzer PFA-100 are longer in neonatal blood compared to cord blood samples. Neonatology, 97(3), 242-249. https://doi.org/10.1159/000253755

59. Strauss, T., Levy-Shraga, Y., Ravid, B., Schushan-Eisen, I., Maayan-Metzger, A., Kuint, J., \& Kenet, G. (2010). Clot formation of neonates tested by thromboelastography correlates with gestational age. Thrombosis and haemostasis, 103(2), 344-350. https://doi.org/10.1160/TH09-05-0282

60. Malamitsi-Puchner, A., Protonotariou, E., Boutsikou, T., Makrakis, E., Sarandakou, A., \& Creatsas, G. (2005). The influence of the mode of delivery on circulating cytokine concentrations in the perinatal period. Early human development, 81(4), 387-392. https://doi.org/10.1016/j.earlhumdev.2004.10.017 
61. Gedikbaşi, A., Salihoğlu, Ö., Çankaya, A., Arica, V., Akkuş, C. h., Hatipoğlu, S., \& Yaşar, L. (2014). The evaluation of cord blood interleukin-1 $\beta$ levels in normal and caesarean deliveries. Human \& experimental toxicology, 33(12), 1193-1198. https://doi.org/10.1177/0960327113499049

62. Treviño-Garza, C., Villarreal-Martínez, L., Estrada-Zúñiga, C. M., Leal-Treviño, M., RodríguezBalderrama, I., Nieto-Sanjuanero, A., Cárdenas-Del Castillo, B., Montes-Tapia, F. F., \& de la O-Cavazos, M. (2016). Leptin, IL-6 and TNF-a levels in umbilical cord blood of healthy term newborns in relation to mode of delivery. Journal of obstetrics and gynaecology : the journal of the Institute of Obstetrics and Gynaecology, 36(6), 719-721. https://doi.org/10.3109/01443615.2016.1148128

63. Kaser, A., Brandacher, G., Steurer, W., Kaser, S., Offner, F. A., Zoller, H., Theurl, I., Widder, W., Molnar, C., Ludwiczek, O., Atkins, M. B., Mier, J. W., \& Tilg, H. (2001). Interleukin-6 stimulates thrombopoiesis through thrombopoietin: role in inflammatory thrombocytosis. Blood, 98(9), 2720-2725. https://doi.org/10.1182/blood.v98.9.2720

64. Kerr, R., Stirling, D., \& Ludlam, C. A. (2001). Interleukin 6 and haemostasis. British journal of haematology, 115(1), 3-12. https://doi.org/10.1046/j.1365-2141.2001.03061.x

65. Oleksowicz, L., Mrowiec, Z., Zuckerman, D., Isaacs, R., Dutcher, J., \& Puszkin, E. (1994). Platelet activation induced by interleukin-6: evidence for a mechanism involving arachidonic acid metabolism. Thrombosis and haemostasis, 72(2), 302-308.66. Beaulieu, L.M., et al., Interleukin 1 receptor 1 and interleukin 1 beta regulate megakaryocyte maturation, platelet activation, and transcript profile during inflammation in mice and humans. Arterioscler Thromb Vasc Biol, 2014. 34(3): p. 552-64.

67. Bester, J., Pretorius, E.(2016) Effects of IL-1 $\beta$, IL-6 and IL-8 on erythrocytes, platelets and clot viscoelasticity. Sci Rep 6, 32188. https://doi.org/10.1038/srep32188

68. Odoom, J. A., Dokter, P. W., Sturk, A., Ten Cate, J. W., Sih, I. L., \& Bovill, J. G. (1988). The influence of epidural analgesia on platelet function and correlation with plasma bupivacaine concentrations. European journal of anaesthesiology, 5(5), 305-312.

69. Sridhar, K., Murphy, D., Shorten, G. (2004) Effects of lignocaine on platelet activating factor production. European Journal of Anaesthesiology 21:55

70. Porter, J., Crowe, B., Cahill, M., \& Shorten, G. (2001). The effects of ropivacaine hydrochloride on platelet function: an assessment using the platelet function analyser (PFA-100). Anaesthesia, 56(1), 1518. https://doi.org/10.1046/j.1365-2044.2001.01760.x

71. Brown, C. H., 3rd, Bradshaw, M. J., Natelson, E. A., Alfrey, C. P., Jr, \& Williams, T. W., Jr (1976). Defective platelet function following the administration of penicillin compounds. Blood, 47(6), 949-956.

72. Schulz, C., von Beckerath, O., Okrojek, R., von Beckerath, N., \& Massberg, S. (2010). Platelet dysfunction and inhibition of multiple electrode platelet aggregometry caused by penicillin. Thrombosis 
73. Sheffield, M. J., Lambert, D. K., Baer, V. L., Henry, E., Butler, A., Snow, G. L., \& Christensen, R. D. (2011). Effect of ampicillin on bleeding time in very low birth-weight neonates during the first week after birth. Journal of perinatology : official journal of the California Perinatal Association, 31(7), 477-480. https://doi.org/10.1038/jp.2010.154

74. Sheffield, M. J., Lambert, D. K., Henry, E., \& Christensen, R. D. (2010). Effect of ampicillin on the bleeding time of neonatal intensive care unit patients. Journal of perinatology : official journal of the California Perinatal Association, 30(8), 527-530. https://doi.org/10.1038/jp.2009.192

75. Burroughs, S. F., \& Johnson, G. J. (1990). Beta-lactam antibiotic-induced platelet dysfunction: evidence for irreversible inhibition of platelet activation in vitro and in vivo after prolonged exposure to penicillin. Blood, 75(7), 1473-1480.

\section{Figures}
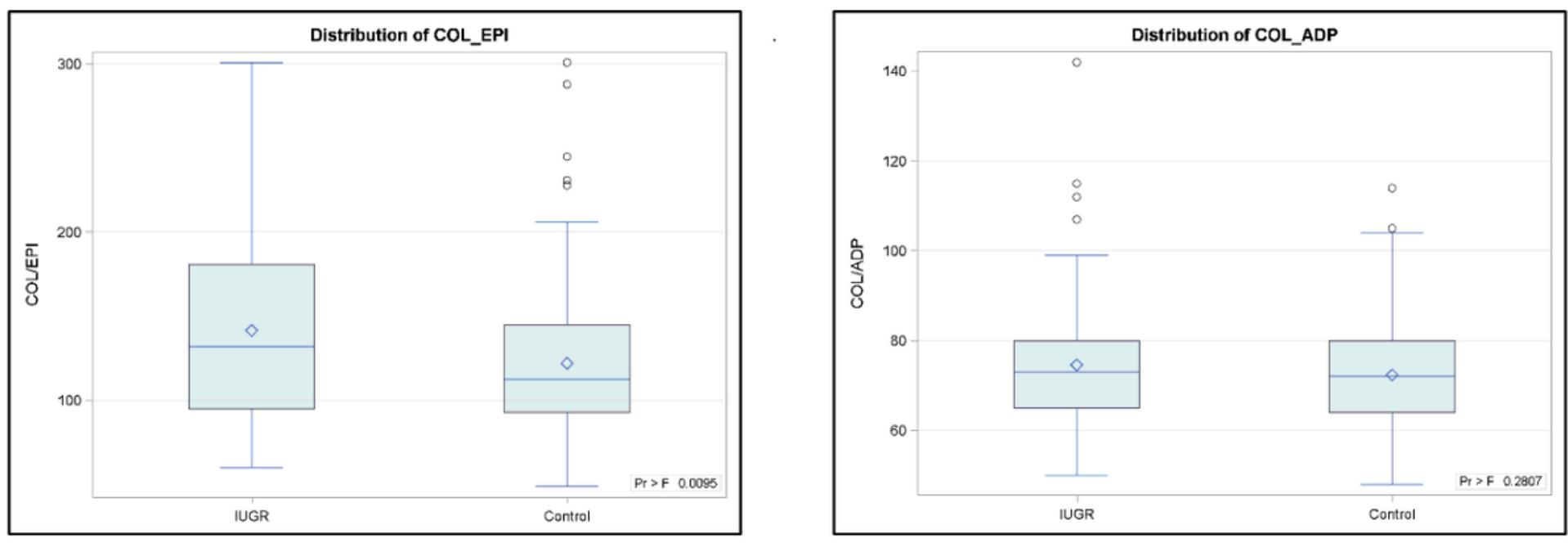

\section{Figure 1}

Box and Whisker plots comparing COL/EPI and COL/ADP CTs between IUGR and control neonates 

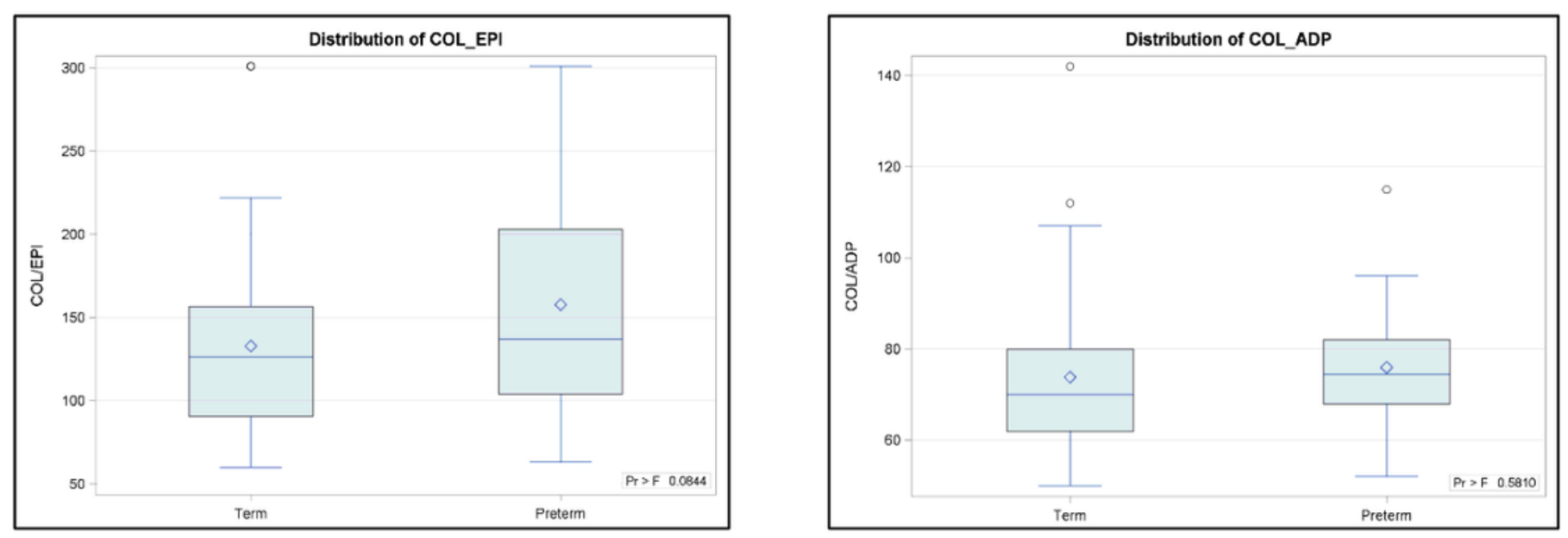

Figure 2

Box and Whisker plots comparing COL/EPI and COL/ADP CTs between term and preterm IUGR neonates 